\title{
An Unusual Complication of Chronic Suppurative Otitis Media: Bezold Abscess Progressing to Scapular Abscess
}

\author{
Rabindra Pradhananga ${ }^{1}$ \\ ${ }^{1}$ Department of ENT-Head \& Neck Surgery, Tribhuvan University \\ Teaching Hospital, Kathmandu, Nepal \\ Int Arch Otorhinolaryngol 2014;18:412-414.
}

\begin{abstract}
Address for correspondence Rabindra Pradhananga, MBBS, MS (ENT-HNS), Department of ENT-Head \& Neck Surgery, Tribhuvan University Teaching Hospital, Kathmandu, Nepal Kathamandu +977 , Nepal (e-mail: rabindrabp@yahoo.com; rabindra9034@gmail.com).
\end{abstract}

\begin{abstract}
Introduction Suppurative otitis media is still the most common ear disease in developing countries. Otogenic complications of this disease have decreased considerably because of the advent of antibiotics, and few rare complications have been encountered.

Objective To report a case of a patient with scapular abscess and lumber cellulitis that had progressed from Bezold abscess as a complication of squamous-type chronic suppurative otitis media.

Resumed Report A 14-year-old girl presented with foul-smelling, purulent, left ear discharge of 1-year duration and decreased hearing on same ear of 6-month duration. She developed painful swelling in left side of neck with restricted neck movement and

Keywords

- abscess

- cellulitis

- mastoiditis

- suppurative otitis media high-grade fever of 3-day duration and swelling over the left scapular area of 1-day duration. The examination and investigation diagnosed squamous-type chronic suppurative otitis media with Bezold abscess progressing to scapular abscess and lumber cellulitis.

Final Comment Chronic suppurative otitis media can lead to abscess in any part of body.
\end{abstract}

\section{Introduction}

Chronic suppurative otitis media (CSOM) is still the most common ear disease in developing countries. Mucosal-type CSOM is more common than squamous-type CSOM. Antibiotics in the treatment of otitis media have significantly decreased the incidence of complications; however, the rate of complication of squamous-type CSOM is still significant in southeast Asia. ${ }^{1}$ A common complication is acute mastoiditis, $^{2}$ which may lead to further complication such as abscesses in the neck and brain. Among them, Bezold abscess comprises $1.3 \%$ of complications of CSOM. ${ }^{2}$ Bezold abscess is defined as a complication of acute mastoiditis when the disease passes inferiorly through the medial aspect of the mastoid tip into the sheath of the sternomastoid muscle. Further spread from Bezold abscess is extremely rare.

\section{Review of Literature with Differential Diagnosis}

Few cases have been reported of further spread of Bezold abscess into various other part of the body including intracranial spread. Singh et $\mathrm{al}^{3}$ reported a case of anterior chest wall abscess secondary to Bezold abscess. Similarly, Saha et al ${ }^{4}$ and Dodonova and Triantafilidi ${ }^{5}$ reported cases of spread of otogenic abscess to the lung (lung abscess). Development of lung abscess can be explained as the progression of later sinus thrombophlebitis and is a serious complication of CSOM. received

February 5, 2014

accepted

February 16, 2014

published online

May 28, 2014
DOI http://dx.doi.org/

10.1055/s-0034-1372511. ISSN 1809-9777.
Copyright $(2014$ by Thieme Publicações License terms Ltda, Rio de Janeiro, Brazil
(®) $\Theta \circledast$ 


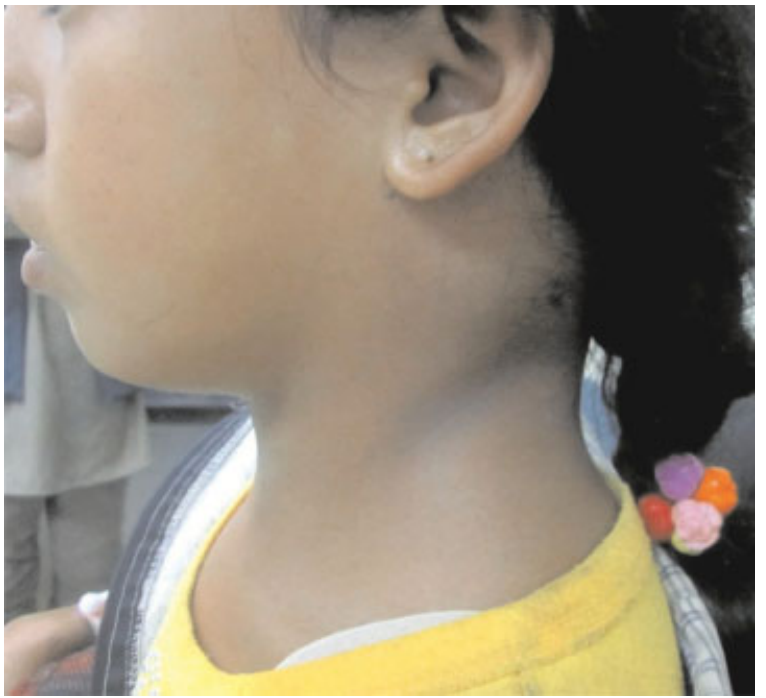

Fig. 1 Swelling over the mastoid and left upper neck.

Common signs and symptoms of Bezold abscess are fever, otalgia, and swelling at the cervical region, otorrhea, restricted cervical mobility, and hypoacusis. Therefore, this case has to be differentiated from other causes of neck abscesses. Computed tomography (CT) is a useful test in this disease, because it allows the identification of pus collections in the cervical region and mastoid involvement. ${ }^{6}$

This report describes a case of Bezold abscess that further spread as scapular abscess and lumber cellulitis as a complication of CSOM.

\section{Case Report}

A 14-year-girl from rural area of Nepal presented with foulsmelling purulent left ear discharge of 1-year duration and decreased hearing in same ear of 6-month duration. She developed painful swelling in left cervical area with restricted neck movement and high-grade fever of 3 days earlier. She also complained of swelling over the left scapular area of 1day duration.

On physical examination, the patient was febrile $\left(102^{\circ} \mathrm{F}\right)$ and with single, diffuse, $8 \times 6-\mathrm{cm}^{2}$ swelling in left side of neck ( - Fig. 1) extending from the left mastoid tip to the lower attachment of the left sternomastoid muscle with erythema-

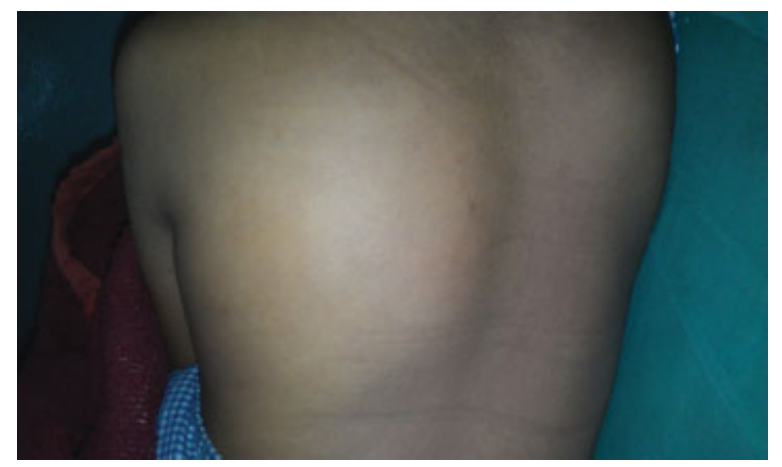

Fig. 2 Scapular swelling.

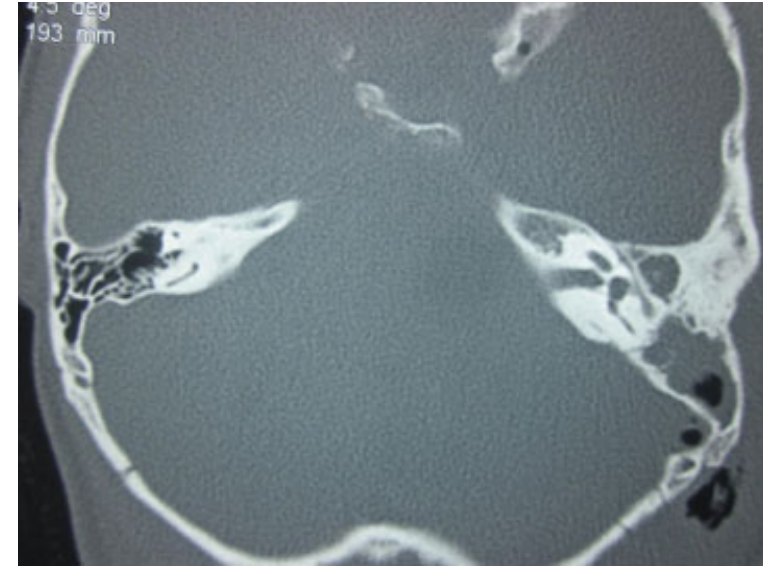

Fig. 3 Computed tomography scan of temporal bone axial cut showing normal right tympanomastoid area with destruction and clouding of left tympanomastoid area.

tous overlying skin. Otoscopy revealed outer attic wall destruction with cholesteatoma.

Routine blood investigations revealed polymorphonuclear leukocytosis and raised erythrocyte sedimentation rate. Audiological investigations showed a left-sided conductive hearing loss of $74 \mathrm{~dB}$. Digital radiography showed air shadow in subcutaneous planes in the left side of the chest. A CT scan revealed air fluid collection in the left mastoid and middle ear cavity (-Fig. 2). There was erosion of mastoid cavity and sinus plate. A defect was noted in the medial wall of the left mastoid cavity. Fluid collection with air foci within was also noted in soft tissue adjacent to left mastoid cavity and extending into neck, suggestive of abscess. Ultrasonography (USG) of the neck showed multiple enlarged lymph nodes in the left side of neck in a posterior triangle, the submandibular area, along the jugular vein. Adjacent soft tissues were edematous with increased vascularity. No definite pocket of collection was noted.

Left modified radical mastoidectomy with type III tympanoplasty was performed and the Bezold abscess was drained under general anesthesia. The mastoid cavity was found to be filled with pus and cholesteatoma debris. A small area of defective bone was found at the mastoid tip, through which there were communications between the mastoid cavity and

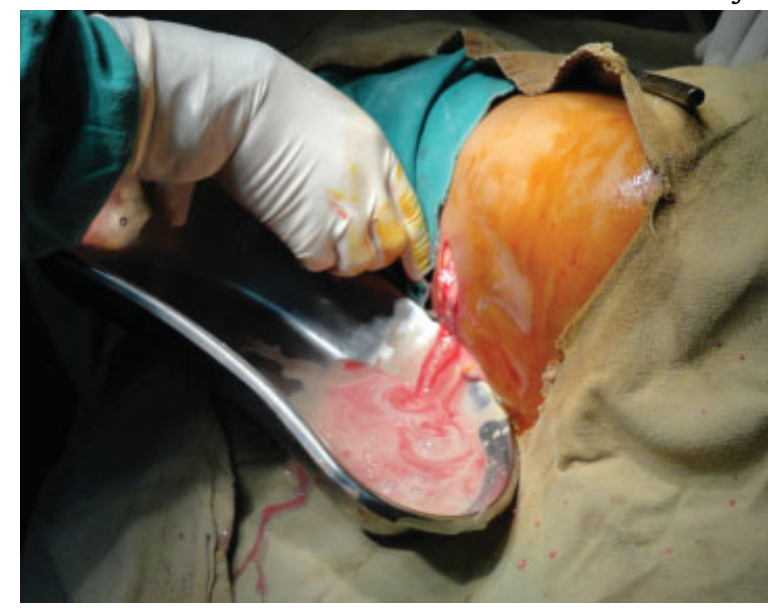

Fig. 4 Incision and drainage (I\&D) of scapular abscess. 
the abscesses in the neck. Thick, foul-smelling pus $(20 \mathrm{~mL})$ was drained through tip cells and digastric ridge. The tract was communicating in the subcutaneous plane in the left scapular region.

The patient was kept under broad-spectrum intravenous antibiotics. Despite antibiotic therapy, on the second postoperative day scapular swelling increased and the patient developed swelling at left lumber area. USG was repeated, focusing on the left scapular region, which showed a $34.7 \times 8.7 \times 35.3-\mathrm{mm}^{3}$ collection in the left scapular region (-Fig. 3) suggestive of subcutaneous abscess with cellulitis. Then $300 \mathrm{~mL}$ of thick foul-smelling pus was drained from the scapular area (-Fig. 4) on the third day of mastoid surgery. The lumbar swelling disappeared with antibiotics within next 2 days. The patient became asymptomatic after 8 weeks.

\section{Discussion}

Otogenic scapular abscess is a rare complication of chronic suppurative otitis media. Complications from otitis media have decreased significantly due to advent of newer antibiotics. However, some patients with otitis media develop serious complications due to delay in diagnosis on the part of physicians, inadequate antibiotic therapy, increased bacterial resistance, negligence by the patients, and concomitant presence of cholesteatoma. ${ }^{7}$ Although cholesteatoma is a benign disease histologically, its behavior may be aggressive locally, and its invasive properties are associated with significant bone destruction leading to other complications like mastoid abscess, meningitis, brain abscess, labyrinthitis, and facial nerve paralysis.

Inflammation and infection may result in necrosis of mastoid process through the digastrics groove. The pus is prevented from reaching the surface by neck musculature but can track along the fascial planes of digastrics or sternomastoid muscle leading to various abscesses like Luc's abscess, Citelli's abscess, and Bezold abscess. ${ }^{8}$ Further spread of Bezold abscess is extremely rare. Singh et al had reported a case of anterior chest wall abscess secondary to Bezold abscess. $^{3}$ The mechanism of spread of Bezold abscess to scapular abscess and lumber cellulitis is not known. It may be spread from facial or subcutaneous plain or hematogenously.

\section{Conclusion}

In case of abscess in any part of body with Bezold abscess, CSOM has to be suspected as one of the primary source of infection.

\section{References}

1 Gupta A, Agrawal SR. A study of prevalence of complications of suppurative otitis media. Ind J Otolaryngol Head Neck Surg 1998; 50(2):140-6

2 Yorganclar E, Yildirim M, Gun R, et al. Complications of chronic suppurative otitis media: a retrospective review. Eur Arch Otorhinolaryngol 2013;270(1):69-76

3 Singh HP, Kumar S, Kumar D, Agrawal A. Otogenic anterior chest wall abscess: a rare and unique presentation of Bezold's abscess. Otorhinolaryngology Clinics: An International Journal 2011;3(2): 90-92

4 Saha SN, Chandra S, Srivastava A, Ghosh A. An unusual complication of CSOM-Lateral sinus thrombosis with lung abscess: a clinicoradiological study. Indian J Otolaryngol Head Neck Surg 2007;59(4):349-352

5 Dodonova ZG, Triantafilidi IG. [Metastatic septic pneumonias and abscesses of the lung in otogenic sepsis]. Vestn Otorinolaringol 1958;20(5):54-57

6 Marioni G, de Filippis C, Tregnaghi A, Marchese-Ragona R, Staffieri A. Bezold's abscess in children: case report and review of the literature. Int J Pediatr Otorhinolaryngol 2001;61(2):173-177

7 Uchida Y, Ueda H, Nakashima T. Bezold's abscess arising with recurrent cholesteatoma 20 years after the first surgery: with a review of the 18 cases published in Japan since 1960. Auris Nasus Larynx 2002;29(4):375-378

8 Spiegel JH, Lustig LR, Lee KC, Murr AH, Schindler RA. Contemporary presentation and management of a spectrum of mastoid abscesses. Laryngoscope 1998;1994(108):779-82 